\title{
ESTADO CHILENO Y COMUNIDAD INDÍGENA. PRESIÓN Y CONFLICTO SOBRE TIERRAS DE USO COLECTIVO EN EL ESPACIO PRECORDILLERANO DE ARICA: PUTRE 1880-1935
}

\author{
Rodrigo Ruz Zagal² y Alberto Díaz Araya ${ }^{3}$
}

\begin{abstract}
Resumen
Se analizan los procesos de presión y conflicto sobre espacios de uso colectivo asociados a comunidades asentadas en Putre (zona precordillerana de Arica). A partir de documentación proveniente de diversos archivos nacionales, regionales y locales, se revisan los elementos de conflicto a partir de la implementación de políticas liberales impulsadas por el Estado chileno posterior a la anexión del territorio post conflicto Guerra del Pacífico (1880) hasta el momento de consolidación del territorio considerado como privado y propiedad del Fisco chileno (1935). Se examinan los procesos de control del espacio territorial a partir de la constitución de propiedad privada e incorporación de sistemas de registros de carácter fiscal, y se analizan las reacciones provocadas en la ciudadanía y población indígena sobre estos influjos destacando la capacidad de reacción, uso e interpretación performática de las políticas estatales frente al uso y tenencia de los espacios comunitarios.
\end{abstract}

Palabras claves: Estado chileno - tierras comunales propiedad de la tierra.

\begin{abstract}
This article studies the pressure and conflict processes concerning collective spaces associated with settled communities in Putre (foothills zone of Arica). Starting from documentation of diverse national, regional and local files, we review the conflict elements of the implementation of liberal politics boosted by the Chilean State after the annexation post War of the Pacific (1880) until the consolidation of the territory now considered private property of the Chilean State (1935). We also examine the processes of control over territorial space based on the constitution of private property and the incorporation of the fiscal system registry, as well as the reactions provoked in the citizens and indigenous population about these influences. We give emphasis to the capacity for reaction, and the use and performative interpretation of state politics in the use and ownership of community spaces.
\end{abstract}

Key words: Chilean State - communal land - land ownership.

Recibido: septiembre 2010. Aceptado: marzo 2011.

\section{* Introducción}

En la precordillera de Arica (extremo norte de Chile), la construcción de los espacios reconocidos como propios por parte de las comunidades indígenas contemporáneas posee orígenes diversos en los que se mezclan permanencias de antiguas prácticas agroganaderas y simbólicas andinas, con especialidades surgidas a partir de la aplicación y entendimiento de políticas estatales (coloniales y republicanas), y la consecuente resignificación que la población ha realizado del territorio y su uso. ${ }^{4}$

A la aplicación de políticas coloniales, tales como la reducción de la población indígena a pueblos y la asignación de espacios repartibles al "común de indios", se deben sumar las políticas republicanas aplicadas por los gobiernos liberales peruanos y chilenos destinados a establecer medidas de regulación jurídica sobre la tierra indígena.

Desde una perspectiva fiscal, la representación de las tierras comunales como "disponibles" o "repartibles", se inició tempranamente, en el régimen peruano (Ruz 2009). Esta situación fue agudizándose hacia mediados del siglo XIX, momento en el cual los proyectos liberales peruanos esbozaron la apertura de un mercado de tierras, característica que, si bien no se logró estructurar en esta etapa, se consolidó bajo la posterior administración chilena post Guerra del Pacífico (González y Gundermann 2009).

El formato para determinar y certificar la propiedad al momento previo del régimen chileno (1880), se encontraba

\footnotetext{
1 Resultado del proyecto FONDECYT 1070032. Convenio de Desempeño Universidad de Tarapacá-Ministerio de Educación.

2 Universidad de Tarapacá, Departamento de Ciencias Históricas y Geográficas. CHILE. Email: rruz@uta.cl

3 Universidad de Tarapacá, Departamento de Ciencias Históricas y Geográficas. CHILE. Email: albertodiaz@uta.cl

4 Los resultados de la investigación obedecen a un estudio de caso, cuyo enfoque no necesariamente corresponde al que se ha aplicado en otras
} 
definido por la legislación de 1828 , en donde se habría determinado la forma en que el gobierno trataría la propiedad de la tierra sobre la base de la gestión de tribunales y notarías a través de todo el Perú, situación que fue complementada posteriormente con la normativa impuesta por el Código Civil de 1852, que perduró hasta comienzos del siglo XX (Figallo 2007).

Al momento de la incorporación de Arica y los poblados circundantes a la soberanía de Chile (1880), 5 la legislación chilena no poseía una política destinada al tratamiento de tierras colectivas o comunitarias dirigida a los segmentos indígenas (con excepción de la legislación hacia tierras mapuche) (Gundermann y González 1997). Una de las modificaciones más importantes destinadas a regular la propiedad fue la implementación de un sistema de registro de propiedad sobre la base del otorgamiento de títulos que certificaban el dominio de un bien. Para ello, el Código Civil chileno definía como única forma de fijar propiedad la inscripción de dominio en los registros de Conservadores de Bienes Raíces [RCBR] (Gundermann 1998), procedimiento que gravitó en el tinte positivista en la comprobación de la propiedad de un bien "documento en mano", así como también generó la apertura de un potencial y progresivo mercado de tierras en la precordillera andina de la zona de Arica, sector donde se concentra esta investigación. ${ }^{6}$

áreas del Norte Grande chileno.

5 Si bien la historiografía tradicional chilena señala el año de término de la Guerra del Pacífico como el punto de partida de la "soberanía" chilena sobre los espacios ocupados, objetivamente la aplicación de la ley chilena se inicia tempranamente en la zona. Por ejemplo, hacia 1880 ya se había abierto en Tacna la Corte de Apelaciones, instancia que permitió a la población local litigar en temas relacionados a tierra y propiedad.

6 En el plano metodológico, se tomó como estudio de caso a la localidad de Putre, situada en plena precordillera de Arica, considerando que en ésta se manifestó una de las pocas instancias legales en donde un colectivo de personas indígenas constituyó propiedad sobre tierras de uso colectivo durante el período en cuestión, definiendo un amplio perímetro territorial como propiedad particular en los años 1909 y 1910. El hecho de que esta comunidad haya inscrito, bajo registros chilenos, tierras de uso colectivo, presenta a esta localidad como atrayente en lo que concierne a la forma como se fue constituyendo la categoría de propiedad a partir del momento de administración chilena, y cómo esto fue afectando a los miembros de la colectividad en el acceso al uso de las tierras comunitarias, proyectando dicha intención a la valoración y uso de las tierras comunales iniciada en el siglo XX.
Las evidencias documentales acerca de la respuesta ejercida por las comunidades indígenas permiten afirmar que la constitución de la propiedad bajo este modelo empezó a definirse hacia 1887, período donde comienzan a verse representados en los registros conservatorios las primeras inscripciones de propiedad (Gundermann 1998). A partir de este año, el tratamiento jurídico en torno a la tierra y su propiedad siguió los caudales formales determinados por los procedimientos legales imperantes en el resto del país. No obstante, el contexto plebiscitario que prosiguió a la Guerra del Pacífico generó un ambiente propagandístico chilenizador que incentivó a que los comuneros indígenas inscribieran sus propiedades bajo la legislación chilena.

En tal escenario, las autoridades chilenas controlaron el acceso a las tierras comunitarias transmitiendo a la población local la intención estatal de considerar las tierras de uso colectivo como fiscales. ${ }^{7}$ El tratamiento de la tenencia de la tierra siguió los procedimientos legales para el registro de la propiedad independientemente del contexto político y sociocultural en el que se aplicaban estas medidas. Esta última mención es importante en la discusión, ya que sobre la base de los pactos que pusieron fin al conflicto (Tratado de Ancón [1883], complementado por el Tratado de Lima [1929]) el Estado chileno propuso la definición de su territorialidad y soberanía a nivel regional, situación que habría traslapado la legislación chilena con la peruana, creando un espacio llano para que tanto los habitantes y propietarios peruanos, como los chilenos, inscribieran sus tierras bajo la ley dominante.

Para 1935, se realiza una inscripción de dominio global que reputa a dominio del Fisco chileno los territorios correspondientes al Departamento de Arica, que no se encontraran inscritos a nombre de privados, resguardando con ello los intereses fiscales ante reclamaciones de particulares, así como también permitió que algunos indígenas andinos pudiesen reputar sus tierras no inscritas como fiscales y acceder a procesos de litigio o de defensa

\footnotetext{
7 Lo que se ha evidenciado a partir de estudios de carácter diagnóstico impulsados por agencias estatales en pro de conocer la realidad jurídica y de ocupación de espacios de uso colectivo, con una visión antropológica-histórica. Ver Ministerio de Bienes Nacionales [MBN] (1999).
} 


\begin{tabular}{|l|c|c|c|c|c|c|c|}
\hline Localidad & $\mathbf{1 8 8 0}$ & $\mathbf{1 8 9 0}$ & $\mathbf{1 9 0 0}$ & $\mathbf{1 9 1 0}$ & $\mathbf{1 9 2 0}$ & $\mathbf{1 9 3 0}$ & Total general \\
\hline Putre & 3 & 20 & 166 & 188 & 44 & 71 & 492 \\
\hline Belén & - & 21 & 104 & 70 & 30 & 11 & 236 \\
\hline Lupica & - & 8 & 2 & 3 & - & - & 13 \\
\hline Saxamar & - & - & 1 & 1 & - & 1 & 3 \\
\hline Socoroma & - & 2 & 58 & 83 & 7 & 17 & 167 \\
\hline Chusmiza & - & - & 1 & - & - & - & 1 \\
\hline Epispacha & - & 1 & 1 & 2 & 2 & 1 & 7 \\
\hline Zapahuira & - & - & 6 & 5 & 1 & - & 12 \\
\hline Copaquilla & - & - & - & - & 2 & 1 & 3 \\
\hline Murmuntani & - & 1 & 8 & 6 & 1 & - & 16 \\
\hline Chapiquiña & 14 & 4 & 15 & 27 & 16 & 41 & 117 \\
\hline Pachama & - & - & 1 & 15 & 2 & 6 & 24 \\
\hline Tignamar & - & 6 & 10 & 66 & 35 & 5 & 122 \\
\hline Indet. & - & - & 17 & 12 & - & 2 & 31 \\
\hline Total general & 17 & 64 & 390 & 479 & 140 & 156 & 1244 \\
\hline
\end{tabular}

Tabla 1. Constitución de propiedades privadas en precordillera andina por decenios (1880-1935) Fuente: MBN (1999).

(González y Gundermann 2009). Si bien la inscripción de propiedades en sectores precordilleranos arranca en los primeros años de la ocupación chilena, ésta mantiene un repunte sistemático durante las primeras décadas del siglo XX (Tabla 1), situación que evidentemente coincide con el endurecimiento de las medidas destinadas por el Estado chileno para crear un contexto propicio preplebiscitario de acuerdo al ambiente diplomático de la época. En tal sentido, este trabajo evalúa los contextos sociohistóricos en los cuales se inserta la problemática de la tenencia de tierras entre las poblaciones andinas del actual norte chileno.

Para el caso de la precordillera de Arica, es posible distinguir el primer decenio del siglo XX como el más severo en la aplicación de políticas de "chilenización violenta", expresadas en una serie de medidas estatales destinadas a fortalecer su presencia en la zona. A saber, el establecimiento y traslado de la Corte de Apelaciones desde Iquique a Tacna, la prohibición de ejercer manifestaciones patrióticas peruanas (izamiento de la bandera patria peruana, celebración de Fiestas Patrias, decretos de prohibición de instrucción primaria por profesorado peruano), entre otras disposiciones (Díaz 2006, Díaz y Ruz 2003).
El decenio posterior (1911 a 1921) es posible reconocerlo como de "consolidación" del control de los territorios. Incluso en términos demográficos, la presencia de chilenos experimentó un alza sustantiva durante este período. Éste es un momento matizado por la posible realización de un plebiscito acordado en el Tratado de Ancón (1883), originando que se alzaran los sentimientos patrióticos, lo que generó un clima beligerante y xenofóbico por parte de los chilenos (Palacios 1974, González 2004). Al momento de iniciarse la etapa de consolidación, Chile ya llevaba en la zona alrededor de 30 años, lo que garantizaba un control efectivo de los territorios y de su población (Yepes 1999).

En este período, la presión ejercida por el Estado chileno se exhibe más agresiva en cuanto al control sobre la propiedad de la tierra. Así, paralelamente a la inscripción de propiedad privada por medios y procedimientos legales, las autoridades chilenas de turno (Subdelegados especialmente), ejercieron un control sobre el acceso a las tierras comunitarias, transmitiendo a la población la intención estatal de considerar tempranamente las tierras de uso colectivo como fiscales.

Dichas disposiciones, sumadas a la pronta apertura de los $\mathrm{RCBR}$, dieron paso a extensos procesos de inscripción de 
propiedades, así como también al elevamiento de solicitudes para ocupar terrenos que, previo al establecimiento del Estado chileno, eran regulados por mecanismos internos de las comunidades y por acuerdos estimados por personas con algún grado de autoridad o prestigio comunitario (Ruz 2005). ${ }^{8}$ A esto, se suma la variable sociopolítica, donde se hostigaba, presionaba y deslegitimaba ante la comunidad a los comuneros relacionados a "sentimientos patrióticos" peruanos, que eran reemplazados por otros comuneros con liderazgo, pero apegados a la causa chilena (Díaz 2006, Díaz y Ruz 2003).9

\section{* LA pérdida del control comunal DEL TERRITORIO}

Durante la administración peruana, existió a nivel regional cierta presión sobre los espacios comunales, lo que a su vez abrió campos de respuestas y reacciones de carácter colectivo ante las solicitudes de privados por el control de algunos espacios comunitarios (Ruz 2009). Esta defensa comunitaria frente a los procedimientos impulsados por el Estado chileno no se hace tan evidente. Es más, durante esta etapa el registro documental parece indicar la pérdida del control sobre estos terrenos aun siendo considerados como fiscales. La documentación circulante del siglo XX se caracteriza

\footnotetext{
8 Una hipótesis alternativa a la problemática que nos convoca (presión y conflicto sobre tierras de uso colectivo representado en documentación jurídico-administrativa de la época) podría sugerir la reacción comunal sobre el control estatal y privado del espacio comunitario. Sin perjuicio de lo anterior, la evidencia documental solo da cuenta de las prácticas objetivas elaboradas por parte de la población local en torno a la privatización de zonas de pastoreo, no así de su intencionalidad. Los casos expuestos persiguen a aquellas intencionalidades, manipulaciones o usos de la población andina frente a los influjos estatales chilenos del período.

9 Situación que, en suma, da cuenta del complejo y heterogéneo panorama de adscripciones sociopolíticas y culturales que, a pesar de no hacerse explícito, da cuenta de una probable permanencia de patrones culturales relacionados a percepciones del espacio, productividad y/o economías nativas. Sin embargo, lo aquí expuesto se vincula predominantemente con las relaciones en base a la "clave estatal", sus representaciones y reacciones frente al registro documental y sus probables interpretaciones, teniendo como premisa orientadora el éxito de los proyectos implementados por la República del Perú y materializados en los programas liberales chilenos (González y Gundermann 2009, Ruz 2009).
}

por ofrecer tipos o formas documentales que negocian el acceso a los recursos por medios extrajudiciales, lo que se diferencia del período peruano, donde se recurre a los medios estipulados por la trama judicial imperante (Díaz et al. 2010).

En la "etapa chilena", los tipos de documentación circulante y que dan cuenta de la situación expuesta, se pueden tipificar en:

\section{Solicitudes de pastoreo}

Las actividades pastoriles ligadas a la ganadería tradicional ovina, bovina y camélida, se vieron insertas dentro una estructura política y jurídica para el otorgamiento de permisos por las autoridades chilenas. Los ganaderos se vieron obligados a solicitar permisos para usar cerros fiscales e inclusive bofedales para ser utilizados como majadas. Las solicitudes destinadas a pastoreo en su mayoría se extendieron en la primera década del siglo XX. ${ }^{10}$ En la memoria anual de 1912, el Subdelegado de Putre se refiere a la condición ganadera del poblado, así como también a las solicitudes de pastoreo en propiedades de carácter Fiscal, señalando que:

"Cuenta en la actualidad con una estención de mas o menos de seiscientas hectáreas de terrenos alfalfados, que unidos a sus grandes extensiones de pastales naturales y cerros con bastante vegetación, extensas montañas de queñoa y grandes extensiones de cerros cubiertas por yareta prometen una abundante explotación de éstos artículos. La ganadería aunque formada todavía por la raza oriunda de éstos lugares no es escasa según: caballares 303, asnales 1309, mulares 175, bovinos 364, ovinos 5877, cabrios 194, porcinos 203, llamos 4.227 y alpacas 2.116 .

Alfalfa seca produce alrededor de dos mil quinientos a tres mil quintales, los que son destinados para abastecer en parte las necesidades del ferrocarril de Arica a La Paz en construcción, las borateras y el importante mineral de Choquelimpie [...].Se han presentado a esta Subdelegación treinta y ocho solicitudes pidiendo permiso para pastear animales en los terrenos fiscales de los cuales se decían dueños los mismos que hoy se presentan solicitando permisos. Aducían como derecho en su favor el haber inscrito en el Conservador de Bienes Raíces esos mismos terrenos y pas-

\footnotetext{
${ }^{10}$ Archivo de la Subdelegación de Putre [en adelante ASP]. Base de datos proyecto FONDECYT 1970644.
} 


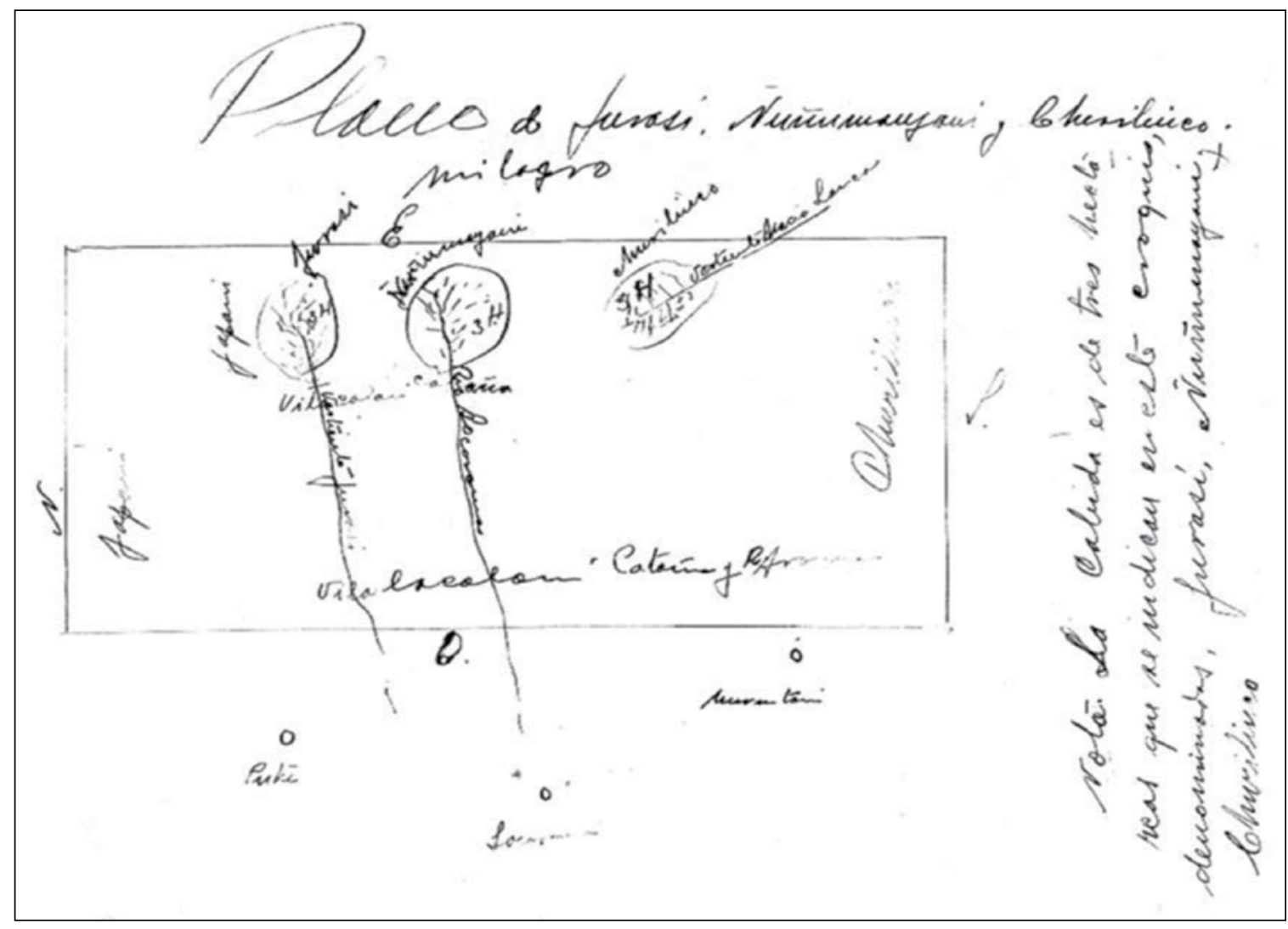

Figura 1. Croquis que acompaña la solicitud de Federico Mamani García para pastorear animales en Jurasi, Ñuñumani y Churilinco. (ASP. Terrenos Fiscales Varios Años. Solicitudes).

tales que hoy reconocen como de propiedad fiscal" (ASP. Libro Registro Informe $\mathrm{N}^{\circ} 3$ y 4. 1926. Año 1926).

Resulta llamativo el reconocimiento por parte de la autoridad del potencial agrícola, productivo y económico de la jurisdicción. También es sugerente la suerte de reconocimiento tácito del carácter fiscal de la propiedad por parte de la comunidad, considerando que se informaron 38 solicitudes para pastoreo en un año, lo cual pareciera ser bastante.

Contrariamente a lo que se puede observar en el período previo a la anexión chilena, donde el uso y acceso a pastales, bofedales y tierras de pastoreo por parte de personas ajenas al poblado era regulado por un grupo de comuneros que poseían cierto grado de prestigio y que se materializaba en oposiciones jurídicas a solicitudes "forasteras" (Ruz 2009), con la administración chilena, hay una suerte de acceso en cierta forma libre para personas de otras localidades, sin la defensa colectiva observada en el período previo.

Un ejemplo es el caso del "forastero" Federico Mamani García (originario de Camiña en el Departamento de Tarapacá), que solicita $-y$ se le otorga- permiso para pastorear sus animales en Putre, solicitando "los pequeños bofedales denominados Jurasi, Nuñumani y Churilinco ubicados en el radio de esta subdelegación y cada uno de tres hectáreas mas o menos en bofedales, cuyas propiedades no tienen dueño alguno por lo tanto son fiscales" (ASP. Terrenos Fiscales Varios Años. Solicitudes) (Figura 1).

En gran parte, las solicitudes eran autorizadas por el Subdelegado, quien conociendo el pulso y la situación local, aprobaba o reprobaba las reparticiones (Ruz 2009).

La tendencia en la concentración de solicitudes para realizar pastoreo en los sectores aledaños al pueblo de Putre 


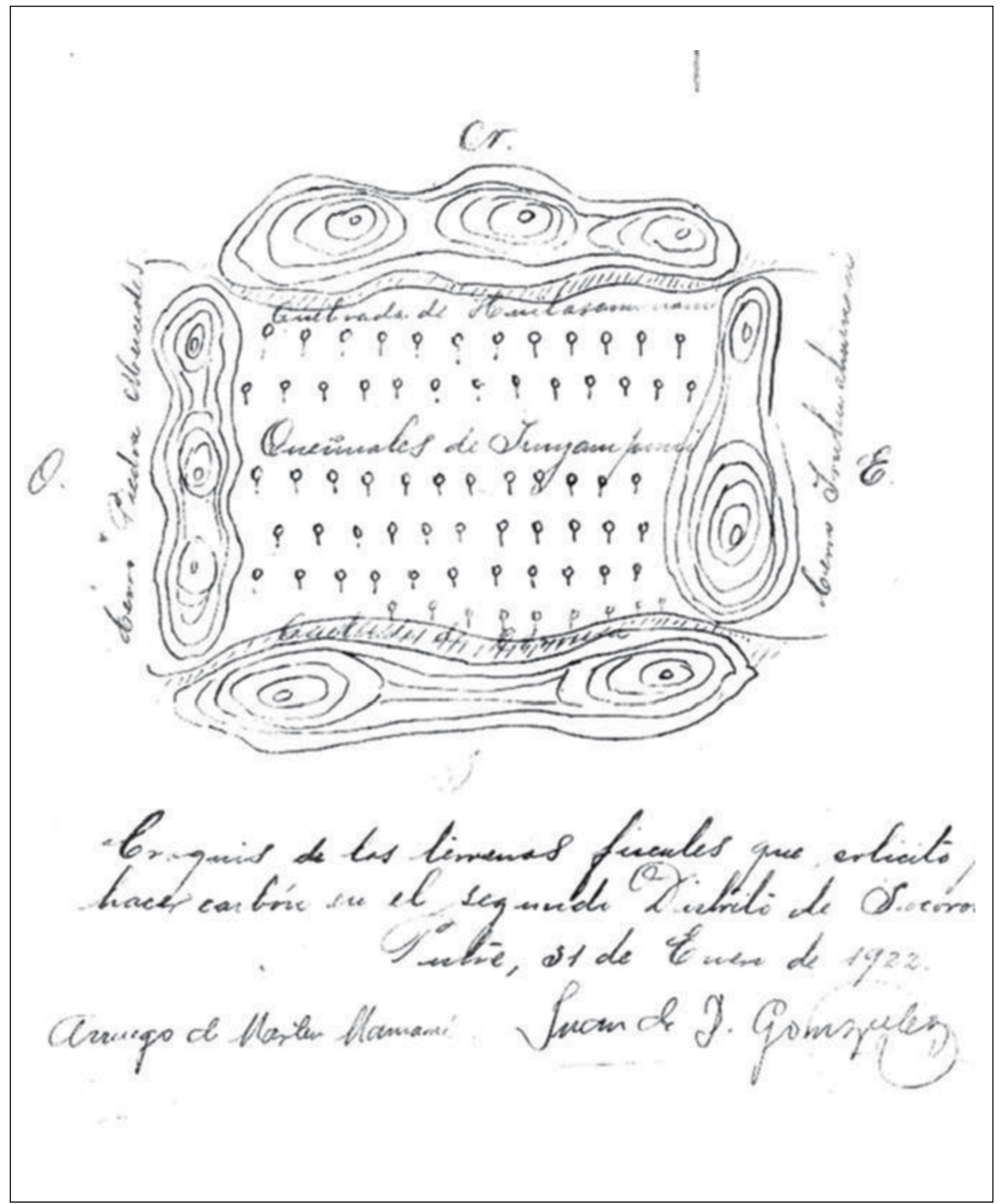

Figura 2. Solicitud de extracción de yareta y queñoa para elaboración de carbón vegetal de Martín Mamani. (ASP. Legajo 1922-1923, Enero - Noviembre). 
se produjo hacia la década de 1920, ${ }^{11}$ fenómeno explicable por el endurecimiento de las medidas tendientes a establecer un manejo pro chileno ante un inminente plebiscito.

\section{Solicitudes para extracción de recursos combustibles}

El uso de los cerros fiscales se extendió de fines ligados a actividades agropastoriles a la inserción de productos extraídos en dicho espacio en circuitos económicos funcionales al abastecimiento de combustible (yareta y/o carbón de queñoa), hacia la ciudad de Arica transportado por el ferrocarril Arica-La Paz (González et al. 1991).

Para el caso, Putre fue la comunidad andina que más activamente participó en estos circuitos de abastecimiento por su relativa cercanía con las estaciones de Puquios y Alcérreca. En los archivos de la Subdelegación de Putre las solicitudes de extracción tanto de yareta como de queñoa se concentran en el decenio de 1920-1930, ${ }^{12}$ período de mayor actividad del ferrocarril de Arica a La Paz.

Las solicitudes hacen mención a terrenos alejados de los centros poblados, en sectores de abundancia de bosques de queñoales y concentración de yareta (pisos ecológicos alto andinos). Otros datos documentales permiten establecer la existencia de una compleja red de extracción que buscaba comercializar el recurso. ${ }^{13}$

El lucrativo negocio de combustible natural seguramente repercutió en las economías locales, algo patente al comprobarse la extensión de muchas solicitudes para su extracción (Figura 2), lo que también conllevó al establecimiento de redes de distribución, transporte y arrieraje de los recursos como pequeñas "empresas". De la información documental se desprende que dichas labores generaron clientelismo y corrupción de ciertas agencias estatales.

El 5 de agosto de 1922 en un oficio confidencial, el Gobernador de Arica informa al Subdelegado de Putre de la denuncia presentada por los vecinos de ese poblado, exponiendo que:

\footnotetext{
${ }^{11}$ ASP. Base de datos Proyecto FONDECYT 1970644.

12 ASP. Base de datos proyecto FONDECYT 1970644.

${ }^{13}$ La documentación del período expresa solicitudes de extracción con diversos fines, entre ellos uno llamativo: cubrir las necesidades energéticas de oficinas salitreras como, por ejemplo, Pedro de Valdivia (ASP. Circulares Oficios Recibidos y Emitidos 1931).
}

"Se han presentado a esta Gobernación los vecinos Martin Mamani y Benedicto Mamani, exponiendo que el Inspector de ese Distrito, Francisco Cerón, les ha cobrado la cantidad de \$3.- para que pudieran venir a éste puerto con una recua de burros con cargas de carbón. Dicen los denunciantes que el referido Inspector ha cobrado también en otras ocasiones sumas de dinero a las personas que bajan trayendo el carbón que explotan en esos lugares, sopretesto que no tienen permiso para sacarlo. A este respecto debo recordar a Ud. que las extracciones de carbón pueden practicarse libremente, pero Ud. deberá otorgar los permisos correspondientes solo a aquellos individuos que respondan al provecho que de ellos pueda obtenerse en un momento dado, y servirá así para que los demás vean los beneficios que tienen los que se mantengan a favor de nuestra causa" (ASP. Legajo Años 1922-1923).

Se entiende que las labores de extracción no son menores, al igual que las redes para conectar los sectores altos con los puntos de abastecimiento: Alcérreca, Puquios y Arica, despertando el interés por funcionarios y mandos medios gubernamentales.

\section{Extracción de recursos mineros}

La asociación de Putre con actividades mineras y el uso de recursos energéticos funcionales a la producción de la azufrera del volcán Tarapacá despertó el interés de empresarios, autoridades y de los mismos comuneros por la explotación de minerales en la zona.

Intereses mineros en los sectores precordilleranos se han identificado desde comienzos del siglo XX. Puntualizando, durante los primeros años del siglo XX, existieron inscripciones de minas azufreras por la población local en acuerdos con afuerinos, afectándose amplios paños territoriales de uso colectivo de épocas anteriores. Por ejemplo, la manifestación de "Azufre Asunta" en Putre:

"Manifestación de solfatera "Asunta" $n^{\circ}$ 1 a 21. Sr. J.L de minas=Félix Urrutiaga ante Us. Por si y por los sres Mariano Maldonado, Frank Bradey, Juan D. Aranda, José e? Aranda, Rudecindo Sarsuri y Eduardo Herrera. Con el debido respeto me presento y digo que ¿? de azufre i? de los nevados Tacapaca y nevada ¿? Putre y de Jaillabe $4^{\circ}$ subdelegación de este departamento. Como descubridor en cerro Virgen. Pido se me conceda 8 pertenencias de 50 hectáreas cada una por mi y por cada una de las personas indicadas arriba a fin de poderlas explotar. Los linderos del pedimento son: por el norte pampa Amache y un cerro denominado Curahuara, por el sur Camino 
Real a Bolivia que sale de Putre; por el este camino que conduce a Putre y pastales de los Yugras y por el oeste pastales de Jaillabe y cerros desconocidos. Designo dichas pertenencias con los nombres de "Asunta" $n^{0} 1$ á 21. Por tanto a Us. suplico se sirva a tener por hecha la manifestación y ordenar el rejistro y publicación conforme a la lei" (Archivo Nacional Judiciales Arica [en adelante ANJA]. Año 1900. Pieza 2, foja 430).

Investigaciones diagnósticas en temas mineros basados en entrevistas sugieren la plena conciencia de la existencia de recursos mineralógicos y desarrollo de pequeña minería entre los años 1910 y $1920 .^{14}$

En términos documentales, podemos señalar que a partir de 1887 se presentan numerosas solicitudes extendidas hacia la Gobernación de Arica para la extracción de pertenencias de bórax en las cercanías de Putre, la mayoría de ellas aceptadas por las autoridades (Tabla 2).

Es necesario argumentar que las actividades mineras si bien se manifestaron tempranamente objetivándose en archivos, no tuvieron una mayor incidencia en la comunidad, no llegando a instancias judiciales. Solo la manifestación minera "Asunta" extendida por comuneros (Aranda, Zarzuri y Maldonado) en asociación con dos "forasteros" (Herrera y Bradey) llegaron a la instancia de "avisaje", no anotándose oposiciones, al menos legales.

\section{* Reacción a la presión externa por el CONTROL DEl ACCESo a la tierRa}

Es llamativa la escasa movilización colectiva frente a las presiones impulsadas por el Estado chileno, así como también frente a solicitudes individuales en los sectores comunitarios de la precordillera andina. Tal como expusimos previamente, la mayoría de las reacciones a las políticas chilenas frente al manejo del tema de la tierra y la propiedad, viene atravesada por conflictos que se explican por la adscripción de comuneros a una identidad sociopolítica peruana.

Con los antecedentes recopilados, no es posible indicar las razones por las cuales se produce esta desmoviliza-

\footnotetext{
${ }^{14}$ Testimonios y registros orales en Instituto de Estudios Indígenas de la Frontera [IEIUFRO] (2005).
}

ción o renuncia colectiva de los lugareños por la tenencia de la tierra comunitaria. Más aún, el registro documental señala que al menos parte de la población realizó inscripciones territoriales por la vía legal en los momentos de mayor presión sobre los territorios.

Casos representativos pueden arrojar pistas acerca del contexto, las presiones y la reacción comunitaria e individual frente a la postura chilena, que no estaba en conocimiento de los procesos de inscripción llevados a cabo por parte de la comunidad o simplemente no consideraron la propiedad legítimamente constituida bajo sus condiciones.

La promoción y difusión del carácter fiscal que adquirirían las propiedades no inscritas en los RCBR, se confrontó directamente con algunos vecinos, que legítimamente desconocieron esta medida aplicada a sus propiedades. De esto se exponen dos casos significativos:

\section{El caso Fondo Huaylas}

El "Fondo Huaylas", estancia ubicada en la quebrada de Huaylas en la zona altiplánica vinculada a Putre, representó en 1914 el choque entre la postura legal y la visión fiscal sobre un espacio disputado: "En Putre, el veintiuno de Enero de mil novecientos catorce, compareció á este Juzgado, á pedido del Sr. Subdelegado, don Nolberto Cabrera, quien expresó que se encontraba en Huaylas pastando animales de propiedad de don Pedro Espada y Manuel Encinas" (Archivo Histórico Vicente Dagnino [en adelante AHVD]. Año 1915, volumen 47). El denunciante señaló "estar pagando á Don Fernando Maldonado (putreño) el forraje que consumen en esos pastales del Fisco i que don Fernando Maldonado le ha dicho que son de su propiedad". Hecha la denuncia, y al contraponerse el hecho a las disposiciones estatales, el Subdelegado Anjel Parada informó al Gobernador la situación de ocupación ilegal de predios fiscales, a la espera -seguramente- de instrucciones, "[L]os terrenos de Huaylas son netamente fiscales, como puede comprobarse con documentos que existen en el archivo de esta Subdelegacion" (AHVD. Año 1915, volumen 47).

La respuesta de la Gobernación incluyó ordenanzas directas del señor ministro de Relaciones Exteriores, que en su respuesta enfatizó que "no permite la ocupacion de terrenos fiscales sin que se obtenga el permiso correspondiente i en 


\begin{tabular}{|c|c|c|c|}
\hline & Yacimiento & Fecha & Detalle \\
\hline \multirow{11}{*}{ Huaylas } & Sin mención & $24 / 04 / 1887$ & Se solicita la extracción de 30 pertenencias de bórax. \\
\hline & Sin mención & $4 / 11 / 1887$ & Se solicita la extracción de 200 pertenencias de yacimiento de bórax. \\
\hline & Sin mención & $4 / 11 / 1887$ & $\begin{array}{l}\text { Se solicita la extracción de } 10 \text { pertenencias de un yacimiento de azufre que se ubica a } 1 \mathrm{~km} \text { de la pampa } \\
\text { Huaylas, que se encuentran a } 20 \mathrm{~km} \text { de Putre. }\end{array}$ \\
\hline & Sin mención & $27 / 09 / 1888$ & $\begin{array}{l}\text { Se solicita la extracción de } 200 \text { pertenencias de yacimiento de bórax, que se ubica a } 100 \mathrm{~m} \text { de la boratera } \\
\text { "Rosa Eloisa" en la pampa Huaylas cerca de Putre. }\end{array}$ \\
\hline & Sin mención & 03/07/1914 & Se solicitan 30 hectáreas. \\
\hline & Sin mención & Sin mención & $\begin{array}{l}\text { Se solicita la extracción de } 200 \text { pertenencias de yacimiento de bórax en la pampa de Huaylas, a } 30 \mathrm{~km} \text { de } \\
\text { Putre. }\end{array}$ \\
\hline & Sin mención & Sin mención & $\begin{array}{l}\text { Se solicita la extracción de } 100 \text { pertenencias de un yacimiento de bórax a } 500 \mathrm{~m} \text {. de la boratera "Rosa } \\
\text { Eloisa" en la pampa Huaylas cerca de Putre. }\end{array}$ \\
\hline & Rosa Eloisa & $\begin{array}{l}7 / 11 / 1887 \\
16 / 07 / 1888 \\
\text { Sin mención }\end{array}$ & $\begin{array}{l}\text { Se concede } 200 \text { pertenencias del yacimiento de bórax. } \\
\text { Se concede la extracción de } 200 \text { pertenencias de yacimiento de bórax. } \\
\text { Se solicita la extracción de } 10 \text { pertenencias de yacimiento de azufre. }\end{array}$ \\
\hline & Salvador & $\begin{array}{l}\text { 7/11/1887 } \\
6 / 07 / 1888 \\
\text { Sin mención }\end{array}$ & $\begin{array}{l}\text { Se concede la extracción de } 10 \text { pertenencias de un yacimiento de azufre. } \\
\text { Se concede la extracción de } 10 \text { pertenencias de yacimiento de azufre. } \\
\text { Se solicita el título definitivo para extraer } 10 \text { pertenencias de yacimiento de bórax. }\end{array}$ \\
\hline & Sara Blanca & $\begin{array}{l}7 / 11 / 1887 \\
16 / 07 / 1888\end{array}$ & $\begin{array}{l}\text { Se concede la extracción de } 100 \text { pertenencias de yacimiento de bórax. } \\
\text { Se concede la extracción de } 100 \text { pertenencias de un yacimiento de bórax. }\end{array}$ \\
\hline & Marte Coralí & $29 / 09 / 1888$ & $\begin{array}{l}\text { Se concede la extracción de } 200 \text { pertenencias de yacimiento de bórax, que se ubica a } 100 \text { m de la boratera } \\
\text { "Rosa Eloisa" en la pampa Huaylas cerca de Putre. }\end{array}$ \\
\hline $\begin{array}{l}\text { Pampa Pasto } \\
\text { Grande }\end{array}$ & Sin mención & $30 / 05 / 1887$ & Se solicita la extracción de 200 pertenencias de yacimiento de bórax que se encuentra cercano a Putre. \\
\hline $\begin{array}{l}\text { Pampa Pasto } \\
\text { Grande }\end{array}$ & Tres Hermanas & $31 / 05 / 1887$ & Se concede la extracción de 200 pertenencias del yacimiento de bórax. \\
\hline Sin mención & San José & $10 / 05 / 1887$ & Se acepta la extracción de 30 pertenencias de bórax a 8 leguas del pueblo de Putre. \\
\hline Sin mención & $\begin{array}{l}\text { Mantos de Santa } \\
\text { Eloisa }\end{array}$ & $10 / 05 / 1887$ & Se concede la extracción de 30 pertenencias de bórax a 8 leguas al Noreste de Putre. \\
\hline Sin mención & Amistad & $10 / 05 / 1887$ & Se concede la extracción de 30 pertenencias de bórax a 8 leguas de Putre. \\
\hline Sin mención & Sin mención & $4 / 11 / 1887$ & Se solicita la extracción de 100 pertenencias de yacimiento de bórax que se ubica a $30 \mathrm{~km}$ de Putre. \\
\hline
\end{tabular}

Tabla 2. Solicitudes mineras en Putre (1887-1901) Fuente: Base de datos proyecto FONDECYT 1970644.

los casos de resistencia como se trata en el del Sr. Maldonado, ha dispuesto que se proceda con la fuerza pública" (AHVD. Año 1915, volumen 47).

Definido el accionar, el Subdelegado envió un contingente de policía para proceder a desalojar la estancia. Una vez en Huaylas, los agentes fueron recibidos por Maldonado y un pastor "con palabras duras i me mostró títulos de propiedad, los que no quiso mostrarme antes que yo procediera $i$ á los que considero ilegales, parece que estaba dispuesto en esos momentos, á hacerme oposición á mis actos, circunstan- cias que me obligaron á proceder con toda enerjía á destruir completamente, en su misma presencia, acompañado del Cabo $i$ de los hombres todo el papal i tambien procedí á traer todos los animales que estaban en los pastales de Huailas i llegando á Putre mandé ante el Juez de Distrito al pastor para que diera una declaracion ante este funcionario i la que acompaño á US" (AHVD. Año 1915, volumen 47).

La exposición de documentos fundantes de propiedad mostrados por parte de Maldonado generó suspicacias entre las autoridades, quienes tras investigar concluyeron que 


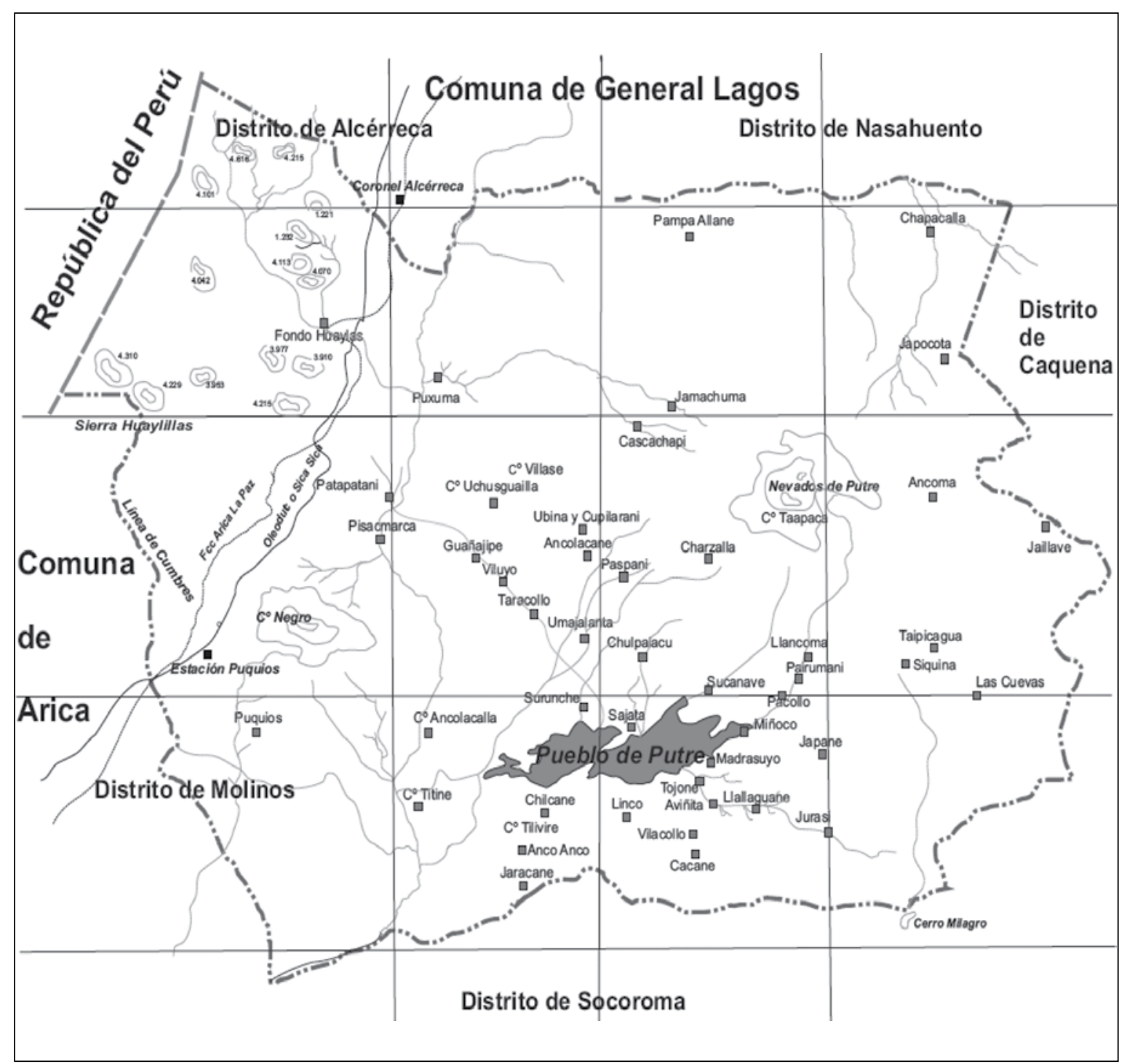

Figura 3. Inscripción de Co-Propiedad "Comunidad Juan de Dios Aranda y otros" y localización de parte de pasturas inscritas.

(Cartografía esquemática). Fuente: Plano n² 27, año 1997 (RCBR Arica).

Maldonado habría solicitado en el año 1909 una pertenencia minera donde edificó para establecerse con un negocio durante las faenas del Ferrocarril de Arica a La Paz.

Las autoridades se encontraban confiadas que Huaylas se hallaba entregada por parte del Gobernador de Arica, según decreto 877 de fecha 17 de diciembre de 1910, a la casa constructora del Ferrocarril de Arica a La Paz, empresa Sir John Jackson. Sin embargo, no contaban que a la fecha del incidente con la inscripción realizada colec- tivamente por "unos veinte vecinos de esta Subdelegación, que inscribieron en el Conservador de Bienes Raices de Arica todos los cerros y pastales naturales, incluyendo tambien Huaylas como de propiedad de lo que ellos llaman La Comunidad de Putre, entre los que figura don Fernando Maldonado" (AHVD. Año 1915, volumen 47).

Seguramente fueron estos documentos los invocados por Maldonado ante la fuerza policial al momento del desalojo. Este acontecimiento mostró bruscamente a 
las autoridades chilenas la forma de accionar de parte de la comunidad: constituir legalmente una amplia propiedad.

Los antecedentes de que disponían las autoridades eran que, antes de la concesión a la constructora Jackson, la estancia Huaylas había sido ocupada por José María Flores, fallecido hace más de 15 años y de ahí a su descendencia Lucas Flores, dejando probablemente como heredero a su hijo José María Flores (ocupante al momento del conflicto). A ciencia cierta no contaban con la oposición de dicha línea parental. Pese a las evidencias de Maldonado (una inscripción "misteriosa"), las autoridades siguieron investigando la situación de Huaylas convocando a un grupo de vecinos a declarar sobre la historia de ocupación y propiedad de la estancia.

En Putre, el 9 de febrero de 1915, los vecinos Claudio Jirón, Mariano Espinoza, Eduardo A. Medina, Julio Vásquez, José S. Herrera, Estanislao Alanoca, Diego Quiguaillo, Orestes Ventura, Felipe Ventura, Hilario Cáceres, Félix Valencia Vázquez, Marcos Alanoca, Matías Choque y Urbano Zarzuri declararon:

"En atención á su atenta que precede, tenemos el agrado de manifestar á Ud. que somos nacidos en Putre, unos i domiciliados largos años otros i jamas hemos sabido i oido decir que los terrenos de Huailas los halla poseido José Maria Flores [...] ni ninguna otra persona. Hoy esos terrenos se los disputan judicialmente entre la Comunidad de este pueblo i el Fisco.

Hace años poselló un tal Lucas Flores un tambo i unos tres topos de terrenos cultivados de alfalfa, en el lugar denominado Allani; como á dos leguas al Noreste de Huailas. José Maria Flores era hijo del propietario i del (hijo) del tambo de Allani i ha fallecido hacen mas de 15 años" (AHVD. Año 1915, volumen 47).

La disputa por Huaylas expuso a las autoridades la existencia de títulos de propiedad privada en tierras consideradas por ellos como "fiscales". Además, entre la "comunidad" fundante de la propiedad se encontraba el acusado Maldonado.

Aun así, el accionar siguió considerando fiscales las tierras circundantes al pueblo de Putre, situación que se agudizó con los años, y que aún es posible observarla, siendo Huaylas considerada en la actualidad como fiscal por ocupantes provenientes del área cordillerana de Alcérreca, ubicada en el altiplano (Ruz 2009).

Una segunda lectura advierte que en el proceso de inscripción realizado por Maldonado y la "comunidad" se omite o desconoce la ocupación e historial del uso de las tierras en Huaylas por parte de la sucesión de José María Flores, quienes aparecen identificados en el documento, pero son obviados por los putreños (Figura 3).

\section{La Co-propiedad Juan de Dios Aranda y otros}

Las principales y mayores inscripciones de propiedad en la zona precordillerana de Arica, que, según la evidencia documental, fueron desconocidas por la autoridad chilena (recién se hizo evidente en 1915, post conflicto por el "Fondo Huaylas"), son las conocidas inscripciones realizadas por 24 comuneros de Putre en el RCBR de Arica en 1909 y 1910 , que sucedieron a la inscripción de los pastos de Ubinas y Cupilarani por Gregoria Cáceres (1906).

Dichas inscripciones se realizaron en cuatro momentos y abarcaron el amplio espacio conocido como la "Comunidad Juan de Dios Aranda y otros". ${ }^{15}$ Las inscripciones fueron registradas en el período más virulento de control chileno en torno a la tierra y en momentos en que -como

${ }^{15}$ En rigor, la comunidad responde a una condición de co-propiedad más que a una corporación o colectividad con el carácter sociológico de "comunidad". Este término responde a una categoría utilizada actualmente por los co-propietarios del paño territorial. No existen antecedentes relacionados al porqué se realizaron cuatro inscripciones. Algunos antecedentes orales hacen referencia a la inscripción inicial de los espacios cercanos a la comunidad (sectores de pastoreo), mientras que en la medida que se avanzaba en los procesos de inscripción se fueron sumando estancias pastoriles y majadas ubicadas en sectores altos. Como señaláramos, hipótesis alternativas sugerirían que el ejercicio del derecho de co-propiedad se vincula con el control del espacio comunitario. Sin embargo, dicho uso, restringido a un cuerpo limitado de propietarios, en el pasado marginó a un porcentaje mayoritario de usuarios de los espacios colectivos. Con el transcurso de los años, esta situación se ha tornado explícita, generando tensión entre los detentores de derechos de los troncos familiares originales que fijaron la propiedad. Por lo demás, el afán comunitarista de dichas hipótesis colisionan con el uso o manipulación de la figura de "colectividad", considerando que ésta permaneció como "letra muerta" durante gran parte del siglo XX, viniéndose solo a regularizar durante la década de 1990, instancias en la cual se retoman las antiguas nomenclaturas relativas a las organizaciones sociales andinas. 
hemos visto- la definición de propiedad fiscal era un imperativo para las autoridades.

Cuatro inscripciones realizadas entre 1909 y 1910 recogen la totalidad del espacio distrital de Putre, inscrito por 24 comuneros en condición de co-propietarios de todo el espacio de la colectividad (Figura 4).16

Estas inscripciones se concretaron en momentos en que las presiones promovidas por los requerimientos esta-

\footnotetext{
${ }^{16}$ RCBR Arica, 1909, No 505 , Fojas 152 , dominio a nombre de Juan de Dios Aranda, Antonio Mollo, Urbano Zarzuri, Diego Quiguaillo, Claudio Jirón, Isidro Cáceres, Mariano Maldonado, Ubaldo Jiménez, Mariano Espinoza, Petrona P. viuda de Jirón, Rosa Ventura viuda de Zarzuri, Oreste Ventura, Felipe Ventura, José Claro Cáceres, Fernando Maldonado, Francisco Calizaya, Julio Vásquez, Juana L. viuda de Jirón, Manuel Ramos, Rosendo Ochoa, Emeterio C. Medina, sobre pastales Las Cuevas, Ancohoma, Siquina, Taipicagua, Jurasi, Payrumani, Guaylloco, Sucanave, Picoco, Cotaña, Llancoma, Madrasuyo, Japane, Villacane, Llallaguane, Pacollo, Ñunumane y Milagro.

RCBR Arica, 1910, N 506, Fojas 153, dominio de Juan de Dios Aranda, Antonio Mollo, Urbano Zarzuri, Diego Quiguaillo, Claudio Jirón, Isidro Cáceres, Mariano Maldonado, Ubaldo Jiménez, Mariano Espinoza, Petrona P. Viuda de Jirón, Rosa Ventura viuda de Zarzuri, Oreste Ventura, Felipe Ventura, José Claro Cáceres, Fernando Maldonado, Francisco Calizaya, Julio Vásquez, Juana L. viuda de Jirón, Manuel Ramos, Rosendo Ochoa, Emeterio C. Medina, sobre pastales Chilcane, Vilacollo, Aviñita, Tojone, Linco, Cacane, Anco Anco, Jacarane, Tilivire y Alguaciña.

RCBR Arica, 1910, No 507, Fojas 153 vta., dominio de Juan de Dios Aranda, Antonio Mollo, Urbano Zarzuri, Diego Quiguaillo, Claudio Jirón, Isidro Cáceres, Mariano Maldonado, Ubaldo Jiménez, Mariano Espinoza, Petrona P. viuda de Jirón, Rosa Ventura viuda de Zarzuri, Oreste Ventura, Felipe Ventura, José Claro Cáceres, Fernando Maldonado, Francisco Calizaya, Julio Vásquez, Juana L. viuda de Jirón, Manuel Ramos, Rosendo Ochoa, Emeterio C. Medina, sobre pastales Chapacalla, Amachuma, Cascachapi, Allane, Pucsuma, Villase, Uchusguailla, Guañasipa, Viluyo, Piñuta, Piscacomarca, Ancolacaya, Patapatani, Guaillas y Puquios. RCBR Año 1910, N ${ }^{\circ}$ 507, Fojas 154,dominio de Juan de Dios Aranda, Antonio Mollo, Urbano Zarzuri, Diego Quiguaillo, Claudio Jirón, Isidro Cáceres, Mariano Maldonado, Ubaldo Jiménez, Mariano Espinoza, Petrona P. viuda de Jirón, Rosa Ventura Viuda de Zarzuri, Oreste Ventura, Felipe Ventura, José Claro Cáceres, Fernando Maldonado, Francisco Calizaya, Julio Vásquez, Juana L. viuda de Jirón, Manuel Ramos, Rosendo Ochoa, Emeterio C. Medina, sobre pastales Umajalanta [en títulos posteriores mencionado como Umacsa], Chilapolaco, Sajata, Surunche, Paspane, Chazalla, Ancolacane, Taracollo, Titire y Aruzcallane.
}

tales "anunciaban" pero no concretaban la inscripción a nombre del Fisco chileno de las propiedades no inscritas en los Registros Conservadores. Estas "amenazas" surtieron el efecto esperado en gran parte de las propiedades menores asociadas al uso individual (chacras, eras, potreros, huertos, casas), pero no en las tierras de uso colectivo, donde su utilización tradicionalmente pasaba por el reconocimiento social de dicha ocupación.

Paradójicamente, el proceso de inscripción privada es contemporáneo con la pérdida de control comunal del espacio, representado en el desconocimiento de la propiedad por parte la administración chilena, que dispuso de estos terrenos como si fuesen fiscales. ${ }^{17}$

En la búsqueda de respuestas a las motivaciones que expliquen dicha inscripción y la urgencia por hacerlo, así como también la "desmovilización" comunal frente a la pérdida de control sobre la circunscripción comunitaria, se torna necesario hallar evidencias para el contexto preplebiscitario en el que se circunscribió aquel proceso de definición de propiedad.

\section{* Política y visibilidad sobre el CONFLICTO POR LA TIERRA}

Las diversas medidas adoptadas por la administración chilena, si bien siguieron un permanente patrón de conflicto-acuerdos, variaron en ciertos momentos. En períodos políticamente más conflictivos (contexto preplebiscitario), las condicionantes y el control ejercido por las autoridades locales se tornaron mucho más exigentes. Así, los dispositivos de otorgamiento de permisos a solicitantes adquirió gradualmente una tonalidad que permitió disponer de lealtades a la causa chilena, tal como se distingue a continuación:

"Señor Subdelegado, En respuesta a su oficio $N^{\circ} 5$ de fecha 30 de Enero próximo pasado, digo a $U d$. que por las razones que hace valer en él, no se hará a Leonardo Rocha Orozco el arrendamiento del terreno fiscal denominado "Amani", salvo que Ud.

\footnotetext{
${ }^{17}$ Queda pendiente establecer vínculos que expliquen la motivación que pudo responder a intereses privados que buscaron aprovechar la instancia de inscribir los terrenos distritales como de la comunidad.
} 


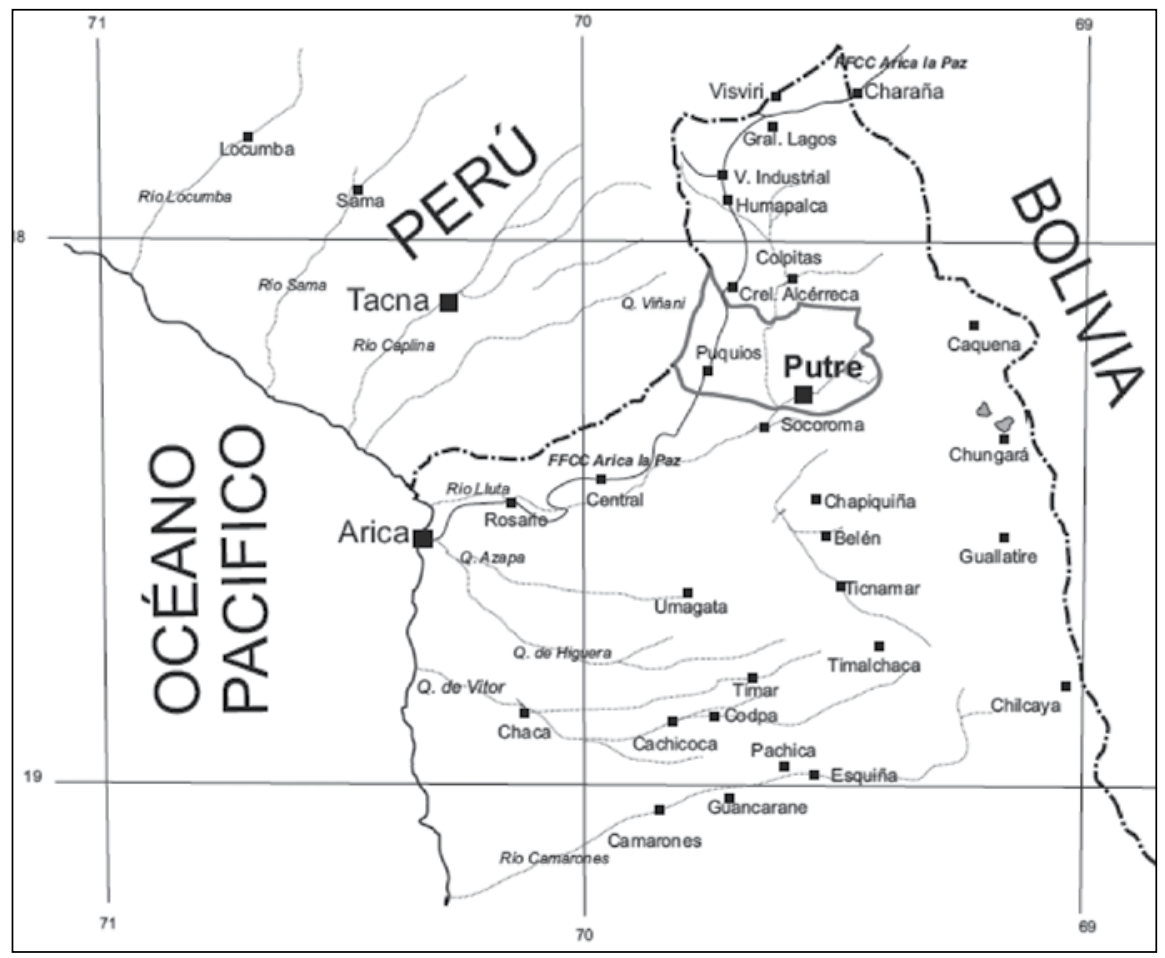

Figura 4. Ubicación y deslindes (línea gris) de la "Comunidad Juan de Dios Aranda" (Cartografía esquemática). Fuente: Plano 27, año 1997 (RCBR Arica).

considere que por medio de este arrendamiento este individuo modifique la actitud que ha tenido hasta ahora y se consiguiera su ayuda efectiva.

Sírvase informarme si habría algun chileno que se interesara por la concesión y si sabe Ud. si el terreno está ó no inscrito a favor del Fisco. Saluda á Ud. Emiliano Bustos. Gobernación de Arica" (ASP. Legajo Años 1922-1923).

El criterio de otorgamiento de concesiones a "interesados" expresa la motivación nacionalista en la asignación de sectores de pastoreo, en este caso "Amani" (sector de pastoreo de "seco" en el sector bajo de la quebrada de $\mathrm{Pu}-$ tre) a personas "chilenas".

Estos criterios de repartición no son aislados, complementándose con el estricto control de los "sentimientos patrióticos" en toda la precordillera andina. A saber:

"El solicitante (del predio, Martín Apaz) no figura en el censo levantado en Diciembre último. Solo aparecer alli Lorenzo Apaz
Choque, sin indicación de sentimientos patrióticos. Es conveniente por tanto, que me dé mayores antecedentes sobre el peticionario, especialmente sobre su nacionalidad y sentimientos, asi como de las ventajas que haya en acoger la petición. Saluda a Ud. Emiliano Bustos" (ASP. Legajo Años 1922-1923).

Sin duda que con la administración chilena, los criterios nacionalistas desplegados hacia la década de 1920 afectaron los protocolos establecidos. ${ }^{18}$ El 30 de enero de 1923 se negó la solicitud de Leonardo Rocha Orozco a una concesión fiscal ocupada por largo tiempo, como lo certifica el agente: "los terrenos que hoy solicita los está ocupando desde hace treinta años, dedicados al pastaje de ganado $i$ sin haber jamas pagado un centavo de arrendamiento". La negación fue emanada desde la Gobernación, argumentándose que el solicitante es "de nacionalidad boliviana $i[e s]$ ademas un elemento pernicioso para nuestra causa" (ASP. Legajo Años 1922-1923).

\footnotetext{
${ }^{18}$ Tendientes a establecer un panorama proclive a la causa chilena en el período pre-plebiscitario (Díaz 2006).
} 
La extensión de los criterios "chilenos" puede visualizarse el 17 de diciembre de 1914. En dicho año, Emiliano Herrera, en su condición de oficial civil, informa a Anjel Parada (Subdelegado), de las acciones llevadas a cabo por los Delegados de Aguas y Comisarios de Aguas Fernando Maldonado y Marcos Alanoca respectivamente, sobre medidas tendientes a contrarrestar las políticas chilenas en tono a la declaración de tierras fiscales.

Se indica que los encargados de aguas cobrarían dineros a los comuneros y "mitarios" con el objeto de "iniciar un juicio de los terrenos que el Fisco pretende adueñarse", ello "bajo apercibimiento de privarles el agua que usan para sus chacras" (ASP. Terrenos Fiscales Varios Años. Solicitudes.) El oficial finalmente sugiere iniciar acciones en contra de "la comunidad de peruanos" y contra el delegado y comisario.

La existencia de una reticencia frente a las comunidades, que si bien no tenían representación jurídica, era efectiva entre las autoridades chilenas, situación que se torna explícita en un oficio de la Intendencia dirigido al Subdelegado al señalar que "sirvase Us. tener presente lo relacionado con carteles ú otra publicación referente a inscripciones de propiedades bajo el título de comunidades ó análogas, pues dichos terrenos son netamente fiscales. Obre usía de acuerdo con Tesorero Fiscal i Promotor Fiscal para presentarse Juzgado pidiendo prohibición de inscribir" (ASP. Libro Registro Informes Enero-Diciembre 1914).

Las medidas contra las figuras comunales se tornan explícitas en la localidad vecina de Socoroma, en donde el 12 de diciembre de 1914 se extiende el siguiente oficio desde la Gobernación de Arica:

"Señor Subdelegado. Tengo conocimiento en forma absolutamente cierta de que en el pueblo de Socoroma se han estado celebrando últimamente reuniones reservadas de vecinos para acordar la resistencia a la autoridad del infrascrito en lo que se refiere a las medidas adoptadas para amparar las propiedades fiscales. Hace cabeza en estas reuniones el señor don José Mariano Humire. Se que se ha obligado por estos señores a cada vecino hombre o mujer

\footnotetext{
${ }^{19}$ Mitarios o Mitayos corresponde a un término quechua que da cuenta de un sistema de turnos para acceder a los cursos de agua o a los horarios de regadío para irrigar las terrazas de cultivos o chacras.
}

a pagar dos pesos abogado que sostenga ante los tribunales sus pretendidos derechos a los terrenos fiscales. Es estraño que Ud. o no tenga conocimiento de estas cosas que pasan en la Subdelegacion de su cargo, o que teniéndolo no se haya $U d$. apresurado a comunicarlo al infrascrito" (ASP. Libro Registro Informes Enero-Diciembre 1914).

El manejo político en torno a la tierra durante el período pre-plebiscitario tuvo un tratamiento sutil por parte de la autoridad, ya que la mayoría de los documentos que señalan medidas de hostilización a elementos peruanos figuran como "reservados" o "confidenciales", siendo - como lo hemos argumentado- facultad y responsabilidad del Subdelegado el aplicar dichas medidas.

Lo más probable es que dichas disposiciones hayan sido percibidas por los comuneros que levantaban banderas peruanas. Conocidos son los casos en que las identidades sociopolíticas y nacionales afloraron en estos momentos de ambiente plebiscitario, especialmente en Putre (Díaz y Ruz 2003, Díaz 2006). Sin embargo, es notable la forma en que comuneros abiertamente pro peruanos salvaron dichas situaciones. ${ }^{20}$

La revisión de material documental permite establecer que, desde las primeras décadas del siglo XX, el Estado chileno ejerció presión sobre las tierras comunales, considerándolas disponibles y potencialmente fiscales. No obstante, solamente en el año 1935 el Fisco de Chile realizó una inscripción de dominio global considerando como propiedad del Estado a los territorios que no se encontraran inscritos a nombre de privados a esa fecha, situación que afectó a todas las personas que no respondieron a las políticas chilenas con respecto a la tierra y propiedad.

\footnotetext{
${ }^{20}$ Tal es el caso del comunero Antonio Mollo, quien abiertamente adoptó posturas pro peruanas, llegando incluso a generar enfrentamientos con la administración chilena en períodos sensibles en materia plebiscitaria. En la medida que el "pulso" político cambiaba, Mollo adoptó instancias de negociaciones que lo llevaron incluso a ocupar cargos dentro de la estructura comunitaria aceptados por la administración chilena. De la misma manera, Mollo habría impulsado procesos de litigación sobre tierras utilizando la legislación chilena para inscribir y acceder a titulación de sus propiedades. Al respecto ver Díaz y Ruz (2003), Díaz (2006), González y Gundermann (2009).
} 


\section{* Comentarios finales}

Si bien el proceso de inscripciones ante los registros conservatorios se entendió como una expresión de ciudadanía, ante lo cual la comunidad respondió ejerciendo sus derechos, los antecedentes expuestos indican que existió una miopía por parte de las autoridades chilenas al desconocer los derechos que un grupo de comuneros habían constituido legalmente su propiedad.

Aunque no libre de conflictos, la consolidación del espacio de la "Comunidad de Putre" o "Juan de Dios Aranda y otros" viene a representar una experiencia novedosa y performática en cuanto las respuestas y medios de constitución que comprendió el extenso proceso de conformación de un espacio "apropiado". En su consolidación, se involucraron variables legales, políticas territoriales y productivas experimentadas por los comuneros putreños, estableciendo un nuevo "mapa" y configuración del espacio territorial en las comunidades de precordillera, durante la primera década del siglo XX, que existen hasta el día de hoy.

El proceso de constitución de la propiedad involucró a que parte de la comunidad "asegurara" la titularidad de la propiedad en las primeras décadas del siglo XX. Sin embargo, las autoridades estatales desconocieron en la práctica dichos títulos. Por ello, se presume que los copropietarios poseían un pleno conocimiento de los derechos sobre las tierras andinas, así como la confianza en los procesos jurídicos por sobre las tensiones producidas por el contexto que marcó las relaciones chileno-peruanas post guerra del Pacífico (1883-1929).

La escasa movilización comunitaria en torno a la defensa de espacios colectivos frente a la acción apropiadora ejercida por la administración chilena, si bien pudo deberse a la falta de capacidad de defensa comunal que puede implicar la apropiación interesada sobre territorios que no correspondían a su jurisdicción "nativa" (como pudo ocurrir por ejemplo en el caso de Huaylas, donde se desconoció la ocupación de ganaderos altiplánicos), también puede explicarse por la presión chilena ejercida sobre la comunidad en un marco político de exacerbación nacionalista. No obstante lo anterior, se puede tomar el caso puntual de la "Comunidad Juan de Dios Aranda" como una manifestación que permita entender las motivaciones de una parte de los comuneros por mantener sus derechos de propiedad "en regla" y en sintonía con la legislación imperante.

\section{$\because$ Referencias citadas}

\section{FUENTES PRIMARIAS UTILIZADAS}

\section{Archivos:}

ASP: Archivo Subdelegación de Putre ANJA: Archivo Nacional Judiciales de Arica AHVD: Archivo Histórico Vicente Dagnino RCBR: Registro Conservador de Bienes Raíces

\section{Volúmenes y documentos:}

ASP. Año 1926. Libro Registro Informe $\mathrm{N}^{\circ} 3$ y 4. ASP. Terrenos Fiscales Varios Años. Solicitudes. ASP. Legajo Años 1922-1923, Enero-Noviembre. ASP. Circulares Oficios Recibidos y Emitidos 1931. ASP. Libro Registro Informes Enero-Diciembre 1914. ANJA. Año 1900. Pieza 2, foja 430. AHVD. Año 1915, volumen 47. RCBR Arica. Año 1997, Plano 27. RCBR Arica. Año 1909, Nº 505, Fojas 152.
RCBR Arica. Año 1910, Nº 506, Fojas 153. RCBR Arica. Año 1910, No 507, Fojas 153 vta. RCBR Arica. Año 1910, Nº 507, Fojas 154.

\section{Bibliografía}

DÍAZ, A. 2006. Chilenización y comunidad andina. Escuela, reclutamiento militar y articulaciones en Putre 1883-1929. Tesis de magíster. Universidad Católica del Norte, San Pedro de Atacama.

DÍAZ, A. y R. RUZ, 2003. Cuando se agitaron las banderas. Conflicto y chilenización en la sierra ariqueña. El caso de Antonio Mollo (1901-1926). En Tarapacá un desierto de historias. Historia, cultura y memoria en el norte chileno. Siglos XIX-XX, M. Gálvez, A. Díaz y R. Ruz (Eds.), pp. 61-84. FONDART, Arica.

DÍAZ, A., R. RUZ, y L. GALDAMES, 2011. Participación de la población indígena de Arica y Tarapacá en la política y justicia comunitarias durante el siglo XIX. Estudios Históricos-Jurídicos XXIII: 511-532. 
FIGALLO, G. 2007. Origen, exclusión y reafirmación de las comunidades campesinas del Perú. Editorial San Marcos, Lima.

GONZÁLEZ, S. 2004. El Dios Cautivo. Las ligas patrióticas en la chilenización de Tarapacá (1910 - 1922). LOM ediciones, Santiago.

GONZÁLEZ, H. y H. GUNDERMANN, 2009. Acceso a la propiedad de la Tierra, Comunidad e identidades colectivas entre los Aymaras del Norte de Chile (1821-1930). Chungará 41: 51-70.

GONZÁLEZ, H., H. GUNDERMANN y R. ROJAS, 1991. Diagnóstico y estrategia de desarrollo campesino en la I Región de Tarapacá. Corporación Norte Grande, Taller de Estudios Andinos, Arica.

GUNDERMANN, H. 1998. Comunidad Aymara, identidades colectivas y Estados nacionales en los albores del siglo XX. En $A$ 90 años de los sucesos de la escuela Santa María de Iquique, P. Artaza (Ed.), pp. 153-181. Dibam, LOM Ediciones, Santiago.

GUNDERMANN, H. y H. GONZÁLEZ, 1997. Contribución a la historia de la propiedad aymara. Corporación Nacional de Desarrollo Indígena, Temuco.
INSTITUTO DE ESTUDIOS INDÍGENAS, 2005. Grupos étnicosy minería en pequeña escala en América Latina y el Caribe. Centro internacional de investigaciones para el desarrollo, Temuco.

MINISTERIO DE BIENES NACIONALES, 1999. Estudio catastral complementario de las tierras indígenas de los valles altos de la Comuna de Putre, I Región. II etapa. División Catastro Nacional de los Bienes del Estado, Santiago.

PALACIOS, R. 1974. La Chilenización de Tacna y Arica 1883-1929. Editorial Arica, Lima.

RUZ, R. 2005. Escrituras, olvido y memoria. Títulos de propiedad, olvido y prácticas en la tierra aymara chilena. Siglos XIX-XX. Diálogo Andino 26: 91-108.

2009. La tenencia de tierras comunales como fuente de conflicto en la precordillera de Arica. Putre 1854-1935. Tesis de magíster. Universidad de Tarapacá / Universidad Católica del Norte, Arica.

YEPES, E. 1999. Un plebiscito imposible... Tacna-Arica 1925-1926. Ediciones Análisis, Lima. 